\title{
ANÁLISE POSTURAL E BIOMECÂNICA DE TRABALHADORES EM ABATEDOURO DE FRANGOS DE CORTE ${ }^{1}$
}

\author{
Cinara da Cunha Siqueira Carvalho², Cecília de Fátima Souza ${ }^{3}$, Ilda de Fátima Ferreira Tinôco ${ }^{3}$, \\ Maria de Fátima Araújo Vieira ${ }^{4}$ Luciano José Minette $^{5}$
}

\begin{abstract}
RESUMO
A criação e o consumo de frangos têm aumentado muito nas últimas décadas, isso é devido ao crescimento da população dos grandes centros urbanos. Paralelo a este desenvolvimento, começou-se a prestar atenção na forma como as atividades são realizadas, e como as máquinas, equipamentos e o ambiente na indústria de frangos de corte influenciam na ocorrência de lesões corporais. Baseado nos riscos que as atividades realizadas no abatedouro oferecem objetivou-se com este trabalho avaliar a análise postural e biomecânica dos trabalhadores atuantes em um abatedouro de frangos de corte. As posturas e a biomecânica dos trabalhadores foram analisadas a partir de registros fotográficos do indivíduo em situação de trabalho real. A análise postural foi interpretada a partir do uso do método OWAS (Ovako Working Posture Analyzing System) e para a avaliação biomecânica utilizou-se programa computacional de modelo biomecânico bidimensional de predição de posturas e força (Michigan). De posse dos dados coletados observou-se que as posturas adotadas para realizar o descarregamento das caixas de frangos do caminhão, limpeza do setor de escalda e depenagem, assim como o ato de erguer e empurrar as caixas dos vários setores para a área de congelamento, merecem verificação a curto prazo. Com relação à biomecânica, observou-se que o carregamento de caixas com peças de frangos, advindas tanto da sala de corte e setor de desfiados podem lesionar o cotovelo e ombro dos trabalhadores. Assim, pode-se concluir que o peso das cargas e a adoção de posturas incorretas são responsáveis por injúrias que acometem a saúde dos trabalhadores atuantes no abatedouro.
\end{abstract}

Palavras-chave: ergonomia, avicultura, abatedouro.

ABSTRACT

\section{POSTURAL AND BIOMECHANICALANALYSIS OF WORKERS IN BROILER SLAUGHTERHOUSE}

Poultry raising and consumption have increased greatly in recent decades, specially due to population growth in large urban centers. Parallel to this development, began to pay attention to how activities are performed, and the machinery, equipment and facilities in the broiler industry influence the occurrence of injury. Based on the risk that activities performed at the slaughterhouse present, this work aimed to evaluate the postural and biomechanical analysis of employees working in that facility. Postures and biomechanics of workers were analyzed from photographic records of the individual in a situation of actual work. The postural analysis was interpreted using the OWAS method (Ovako Working Posture Analyzing System) and for the biomechanical evaluation it was used a two-dimensional biomechanical model computer program for predicting postures and strength (Michigan). After collecting all data, it was observed that the postures adopted to unload chicken boxes off the truck and to clean the scalding and plucking sector, as well as the act of lifting and pushing boxes from various sectors to the freezing area, are worth checking in a short term. With respect to biomechanics, it was observed that the loading of boxes with chicken pieces, coming both from the cutting room and the shredded sector, can injure elbows and shoulders of workers. Thus, it can be concluded that the weight of loads and incorrect postures are responsible for injuries that affect the health of employees working in the slaughterhouse.

Keywords: ergonomics, aviculture, slaughterhouse

\section{Recebido para publicação em 06/05/2010. Aprovado em 01/09/2011.}

1 - Parte da Tese de Doutorado do primeiro autor. Projeto financiado pela FAPEMIG

2 - Eng ${ }^{\mathrm{a}}$ Agrícola, Prof ${ }^{\mathrm{a}}$ Doutora, Departamento de Ciências Agrárias, UNIMONTES/Janaúba - MG, cínara.carvalho@unimontes.br

3 - Eng ${ }^{a}$ Agrícola, Prof ${ }^{a}$ Doutora, Departamento de Engenharia Agrícola, UFV/Viçosa - MG

4 - Zootecnista, Mestranda em Engenharia Agrícola, Departamento de Engenharia Agrícola, UFV/Viçosa - MG

5 - Engenheiro Florestal, Prof Doutor, Departamento de Engenharia Elétrica e de Produção, UFV/Viçosa - MG 


\section{INTRODUÇÃO}

A análise postural baseia-se no estudo do posicionamento relativo de partes do corpo, como cabeça, tronco e membros, no espaço. A boa postura é importante para a realização do trabalho sem desconforto e estresse. No entanto, durante determinadas tarefas desenvolvidas em um abatedouro, os trabalhadores podem executar atividades que demandam força e que geram posturas inadequadas. De acordo com Couto (2007), posturas desfavoráveis provocam um aumento de fadiga no trabalhador e levam ao longo do tempo a lesões graves.

Qualquer desvio na forma da coluna vertebral pode gerar solicitações funcionais prejudiciais. Desta forma, Oliver (1999) define a boa postura como a atitude que uma pessoa assume "utilizando a menor quantidade de esforço muscular e, ao mesmo tempo, protegendo as estruturas de suporte contra traumas". Posturas desfavoráveis ocasionam um aumento de fadiga no trabalhador e levam ao longo do tempo a lesões graves, além de serem as maiores causas de afastamento do trabalho e de sofrimento humano (COUTO, 2007).

De acordo com Barth et al. (2010), segmentos como punhos, braços e ombros, seguidos de coluna e pernas compõem os principais membros atingidos nas tarefas desempenhadas na linha de produção do filé.

Associado ao estudo da análise de postura, Dul \& Weerdmeester (1995) sugerem a análise de biomecânica para estimar as tensões que ocorrem nos músculos e articulações durante uma postura ou um movimento, principalmente, quando a atividade em questão requer demasiado esforço físico.

Segundo estudos realizados por Defani (2007) e Delwing (2007), o abate de animais em frigoríficos se apresenta como um problema crescente em relação às doenças ocupacionais, por se tratar de atividades laborais nas quais as pessoas demandam esforços físicos repetitivos e posturas inadequadas, provenientes de uma inadequação ergonômica dos mobiliários e equipamentos e de tarefas extremamente segmentadas.
Baseado no pressuposto de que o serviço realizado em abatedouro pode acometer problemas posturais e lesões em determinados membros do corpo dos trabalhadores, objetivou-se com esse trabalho proceder a um diagnóstico da análise postural e biomecânica dos funcionários atuantes em um abatedouro de frangos de corte.

\section{METODOLOGIA}

O trabalho foi desenvolvido em um abatedouro pertencente a uma empresa comercial, representativa de grande parte da avicultura industrial do Brasil, nos meses de junho e julho de 2008, durante o primeiro turno de trabalho do abatedouro, com início às 03:00, 04:00 e 05:00 horas e término às 13:00, 14:00 e 15:00 horas, respectivamente.

As atividades analisadas foram: descarregamento das caixas de frango, pendura, depenagem, sangria manual, evisceração, manuseios na sala de corte do mercado nacional, sala de cortes para exportação e chiller, separação de pé e miúdos, embalagem da sala de corte e embalagem da sala de cortes para exportação.

O método OWAS (Ovako Working Posture Analysing System) consiste em analisar determinadas atividades em intervalos variáveis ou constantes, observando-se a frequência e o tempo despendido em cada postura, avaliando, desta forma, as posturas adotadas pelos funcionários durante a jornada de trabalho. As posturas foram analisadas a partir de registros fotográficos do indivíduo em situação real de trabalho. Foram considerados as posturas relacionadas ao tronco, braço, pernas e o uso de força necessária para desempenhar uma função, para assim fazer estimativas da proporção do tempo durante o qual as forças são exercidas e posturas assumidas.

\section{$1^{\circ}$ Dígito - Costas}

ereta

Inclinada para frente ou para trás

Torcida ou inclinada para os lados

Inclinada e torcida ou inclinada para frente e para os lados 
$2^{\circ}$ Dígito - Braços

1 - Ambos os braços abaixo do nível dos ombros

2 - Um braço no nível dos ombros ou abaixo

3 - Ambos os braços no nível dos ombros ou abaixo

$3^{\circ}$ Dígito - Pernas

1 - Sentado

2 - De pé com ambas as pernas esticadas

3 - De pé com o peso em uma das pernas esticadas

4 - De pé ou agachado com ambos os joelhos dobrados

5 - De pé ou agachado com um dos joelhos dobrados 6 - Ajoelhado em um ou ambos os joelhos

7 - Andando ou se movendo

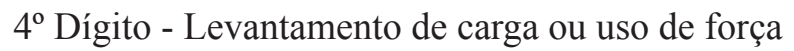
1 - Peso ou força necessária é $10 \mathrm{~kg}$ ou menos

2 - Peso ou força necessária excede $10 \mathrm{~kg}$, mas menor que $20 \mathrm{~kg}$

3 - Peso ou força necessário excede $20 \mathrm{~kg}$.

A combinação das posições das costas, braços, pernas e o uso de força no método OWAS receberam uma pontuação que foi incluída o sistema de análise Win - OWAS, com o que foi possível categorizar níveis de ação para medidas corretivas.

O método então classificou as posturas em 4 categorias:

$1^{\circ}$ : postura normal que dispensa cuidados

$2^{\circ}$ : postura deverá ser verificada durante a próxima rotina de trabalho

$3^{\circ}$ : postura que deve merecer atenção a curto prazo $4^{\circ}$ : postura que deve merecer atenção imediata

A avaliação biomecânica foi feita com base em registros fotográficos feitos com o trabalhador em diversos ângulos, durante a realização de suas atividades. As cargas envolvidas foram anotadas durante a realização do trabalho e usadas como entrada no programa computacional de modelo biomecânico bidimensional de predição de posturas adotadas durante a realização das atividades e de forças estáticas exigidas para a realização destas mesmas atividades. Este programa computacional foi, desenvolvido pela Universidade de Michigan nos Estados Unidos.

O programa biomecânico bidimensional avalia a possibilidade de lesão no ombro, cotovelo, dorso, coxofemoral, joelho e tornozelo. A análise dos resultados fornecidos por este software permite estabelecer a carga limite recomendada, que corresponde ao peso que mais de $99 \%$ dos homens e $75 \%$ das mulheres conseguem levantar.

\section{RESULTADOS E DISCUSSÃO}

Para a avaliação postural, foram analisadas as posturas corporais assumidas pelos trabalhadores do abatedouro e classificadas de acordo com a categoria determinada pelo sistema OWAS. No Quadro 1, lista-se o registro fotográfico das posturas adotadas para determinada tarefa, a combinação das posturas e a categoria na qual essas posturas se classificam.

Quadro 1. Registro fotográfico das posturas no sistema OWAS, considerando as diferentes etapas das atividades realizadas no abatedouro.

\begin{tabular}{ccc}
\hline ETAPA DA ATIVIDADE & POSTURAS & CATEGORIA \\
\hline & & \\
& & \\
& Tronco ereto, com ambos os & \\
braços abaixo dos ombros, & \\
de pé com ambas as pernas & \\
esticadas e peso inferior a 10 & 1 \\
$\mathrm{~kg}$ & 1121 \\
& & \\
& & \\
\hline
\end{tabular}




\begin{tabular}{ccc}
\hline ETAPA DA ATIVIDADE & POSTURAS & CATEGORIA \\
\hline & Tronco ereto, ambos os braços \\
abaixo do nível dos ombros, de \\
pé com as pernas esticadas e \\
peso inferior a $10 \mathrm{~kg}$ \\
1121
\end{tabular}

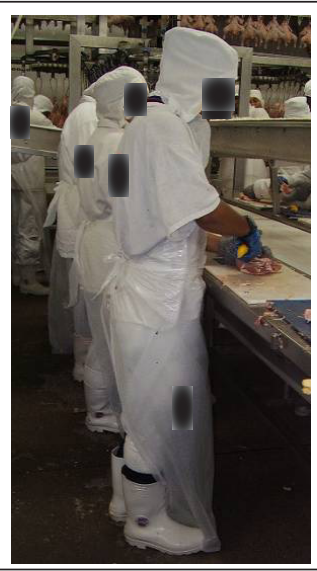

Tronco ereto, com ambos os braços abaixo do nível dos ombros, de pé com as pernas esticadas e peso inferior a $10 \mathrm{~kg}$

1121

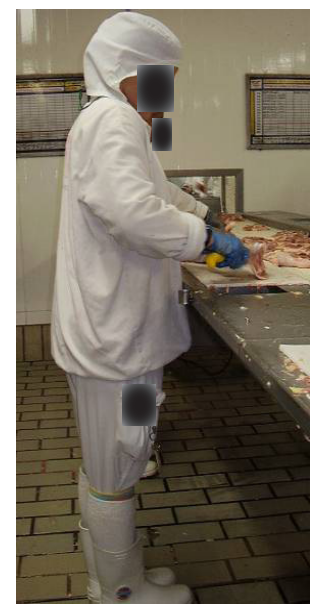

Tronco ereto, com ambos os braços abaixo do nível dos ombros, de pé com as pernas esticadas e peso inferior a $10 \mathrm{~kg}$

1121

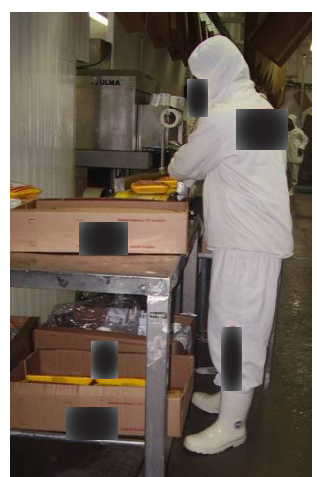

Tronco inclinado para frente, com ambos os braços abaixo do nível dos ombros, de pé com as pernas esticadas e peso inferior

a $10 \mathrm{~kg}$

2121 


\begin{tabular}{ccc}
\hline ETAPA DA ATIVIDADE & POSTURAS & CATEGORIA \\
\hline & $\begin{array}{c}\text { Tronco inclinado para frente, } \\
\text { com ambos os braços abaixo } \\
\text { do nível dos ombros, de pé } \\
\text { com as pernas esticadas e peso } \\
\text { inferior a } 10 \mathrm{~kg} \\
2121\end{array}$ & 1 \\
& & \\
& & \\
\end{tabular}

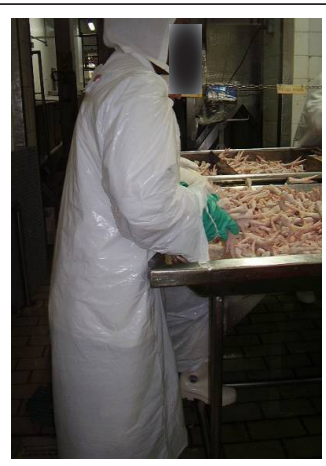

Tronco inclinado para frente, com ambos os braços abaixo do nível dos ombros, de pé com as pernas esticadas e peso $\quad 1$ inferior a $10 \mathrm{~kg}$ 2121

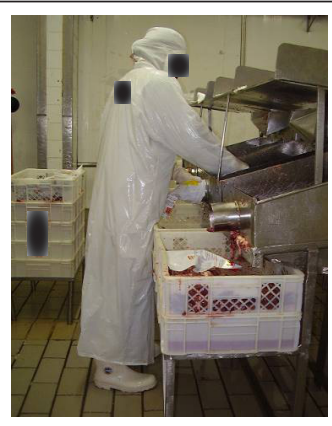

Tronco inclinado para frente, com ambos os braços abaixo do nível dos ombros, de pé com as pernas esticadas e peso inferior a $10 \mathrm{~kg}$ 2121

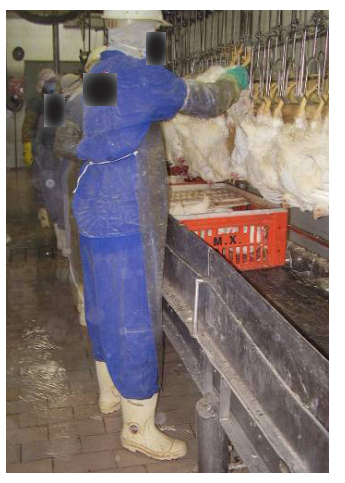

Tronco ereto, com ambos os braços no nível dos ombros, em pé com ambas as pernas esticadas e peso inferior a $10 \mathrm{~kg}$ 


\begin{tabular}{ccc}
\hline ETAPA DA ATIVIDADE & POSTURAS & CATEGORIA \\
\hline Tronco inclinado para frente, \\
com ambos os braços acima do \\
nível dos ombros, de pé com as \\
pernas esticadas e peso inferior \\
a $10 \mathrm{~kg}$ \\
2321
\end{tabular}

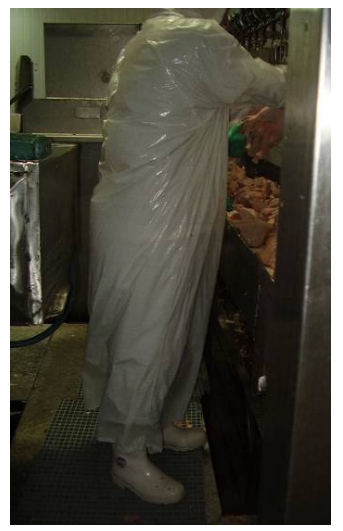

Tronco inclinado para frente, com ambos os braços no nível dos ombros, de pé com o peso em uma das pernas esticadas e peso inferior a $10 \mathrm{~kg}$ 2331

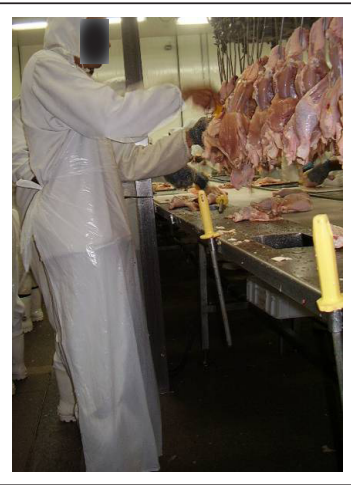

Tronco ereto, com ambos os braços no nível dos ombros, de pé com as pernas esticadas e peso inferior a $10 \mathrm{~kg}$ 


\begin{tabular}{|c|c|c|}
\hline ETAPA DA ATIVIDADE & POSTURAS & CATEGORIA \\
\hline & $\begin{array}{l}\text { Tronco ereto, com ambos os } \\
\text { braços no nível dos ombros, de } \\
\text { pé com as pernas esticadas e } \\
\text { peso inferior a } 10 \mathrm{~kg} \\
1321\end{array}$ & 2 \\
\hline & $\begin{array}{l}\text { Tronco torcido para o lado, } \\
\text { com um braço no nível do } \\
\text { ombro, andando e peso inferior } \\
\text { a } 20 \mathrm{~kg} \\
3272\end{array}$ & 3 \\
\hline MALD & $\begin{array}{l}\text { Tronco inclinado par frente, } \\
\text { com os braços no nível dos } \\
\text { ombros, de pé com os joelhos } \\
\text { dobrados e peso entre } 10 \text { e } 20 \\
\mathrm{~kg} \\
2342\end{array}$ & 3 \\
\hline
\end{tabular}

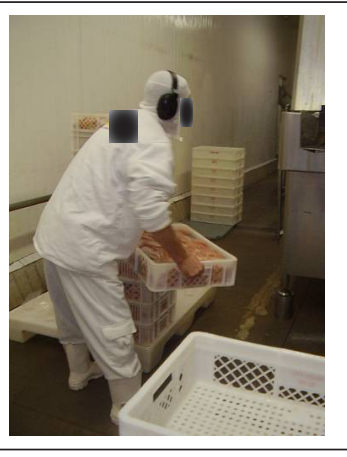

Tronco inclinado para frente, com ambos os braços abaixo do nível dos ombros, de pé com pernas esticadas e peso

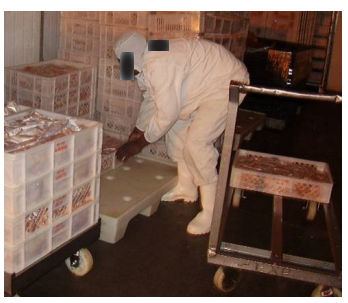
entre 10 e $20 \mathrm{~kg}$ 2122

Tronco inclinado para frente, com ambos os braços no nível dos ombros, agachado e peso entre 10 e $20 \mathrm{~kg}$

\section{2}


As posturas assumidas pelos funcionários para atividades como a sangria manual, evisceração com as mãos abaixadas, o corte das peças de frangos destinadas ao mercado interno e externo na mesa, além de embalar essas peças e separar os miúdos e os pés, foram classificadas como categoria 1 e por isso dispensam cuidados.

Já as posturas adotadas classificadas como categoria 2 e que necessitam ser verificadas a longo prazo foram: a pendura dos frangos na nória para o abate, ajustando a carcaça na nória no setor de escalda e depenagem, levantamento do frango na nória recém-saído do chiller, além do corte das peças de frangos localizados na nória.

As atividades classificadas como categoria 3, para as quais a postura merece verificação a curto prazo, foram identificadas durante o descarregamento das caixas de frangos do caminhão, limpeza do setor de escalda e depenagem e o ato de erguer e empurrar as caixas dos vários setores para a área de congelamento e desfiados.

As posturas assumidas por estes funcionários poderiam ser agravadas e classificadas em outras categorias caso a análise levasse em consideração o número de repetições realizadas pelos trabalhadores.

Para Delwings (2007), os trabalhadores dos setores de abate de aves estão expostos a alta repetitividade de um mesmo padrão de movimento, posturas incorretas dos membros superiores, além da compressão das delicadas estruturas dos membros superiores. O autor ressalva que a repetitividade é um fator de risco importante que, associado a outros fatores como o frio, tem seus efeitos potencializados.

Além disso, para Defani (2007), na maioria das vezes, essas posturas adotadas se tornam mais prejudiciais ainda quando se faz necessária a flexão da coluna cervical, que é exigida pela necessidade de se direcionar o olhar para baixo, para acompanhamento do processo de trabalho.

De acordo com Barth et al. (2010), uma forma de amenizar os efeitos causados no corpo durante as atividades desenvolvidas em um abatedouro de frangos de corte é o rodízio de funções. Os autores verificaram que referências a desconforto/do, foram maiores no ombro direito, mão esquerda, costas média e inferior, antebraços, punhos predomínio direito, pescoço, pernas, braço esquerdo, mão direita e cervical, antes da aplicação de técnicas de rodízio de atividades. A média do desconforto/dor foi menor após a intervenção do rodízio, tanto no início e no final do turno, como ainda em relação aos segmentos analisados, demonstrando que a intervenção na linha de produção de corte do filé reduziu a intensidade de dor de seus trabalhadores durante todo o turno de trabalho.

No Quadro 2 está listado o resumo da análise biomecânica das operações realizadas no abatedouro. Mostra-se, para cada uma das fases destas atividades, se as articulações apresentam ou não algum problema causado pela carga de trabalho. A sigla SRL representa "Sem Risco de Lesão nas Articulações", em que mais de $99 \%$ dos trabalhadores conseguem suportar a carga imposta pela atividade sem risco para as articulações envolvidas, e a sigla CLR representa "Carga Limite Recomendada Ultrapassada", ou seja, em que menos de $99 \%$ dos trabalhadores conseguem suportar a carga imposta pela atividade sem risco para as articulações envolvidas. A numeração representa as seguintes articulações: 1 = ombro, $2=$ cotovelo, $3=$ disco L5/S1 (dorso), $4=$ coxofemorais, $5=$ joelho, $6=$ tornozelo.

Quadro 2. Resumo da análise biomecânica das atividades realizadas no abatedouro

\begin{tabular}{|c|c|c|c|c|c|c|c|c|}
\hline \multirow{2}{*}{ Atividade } & \multirow{2}{*}{$\begin{array}{c}\text { Fase da } \\
\text { operação }\end{array}$} & \multirow{2}{*}{$\begin{array}{c}\text { Postura } \\
\text { estática } \\
\text { selecionada } \\
\text { para análise }\end{array}$} & \multicolumn{6}{|c|}{$\begin{array}{l}\text { Articulações e suas respectivas } \\
\text { condições de suportar a carga }\end{array}$} \\
\hline & & & 1 & 2 & 3 & 4 & 5 & 6 \\
\hline $\begin{array}{c}\text { Descarregamento } \\
\text { de caixas de } \\
\text { frangos do } \\
\text { caminhão }\end{array}$ & $\begin{array}{l}\text { Descarregando } \\
\text { as caixas do } \\
\text { frangos }\end{array}$ & & SRL & SRL & SRL & SRL & SRL & SRL \\
\hline
\end{tabular}




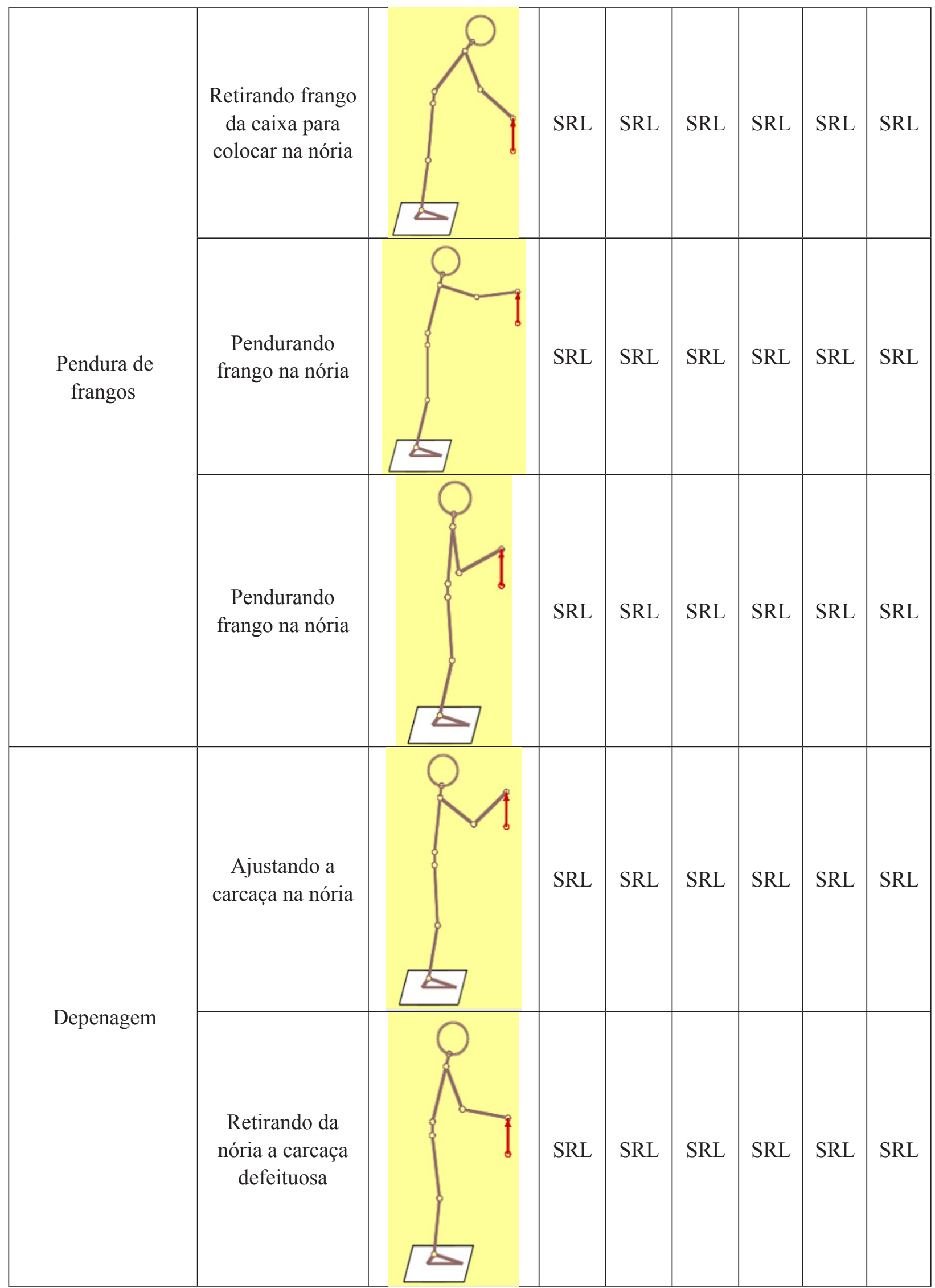




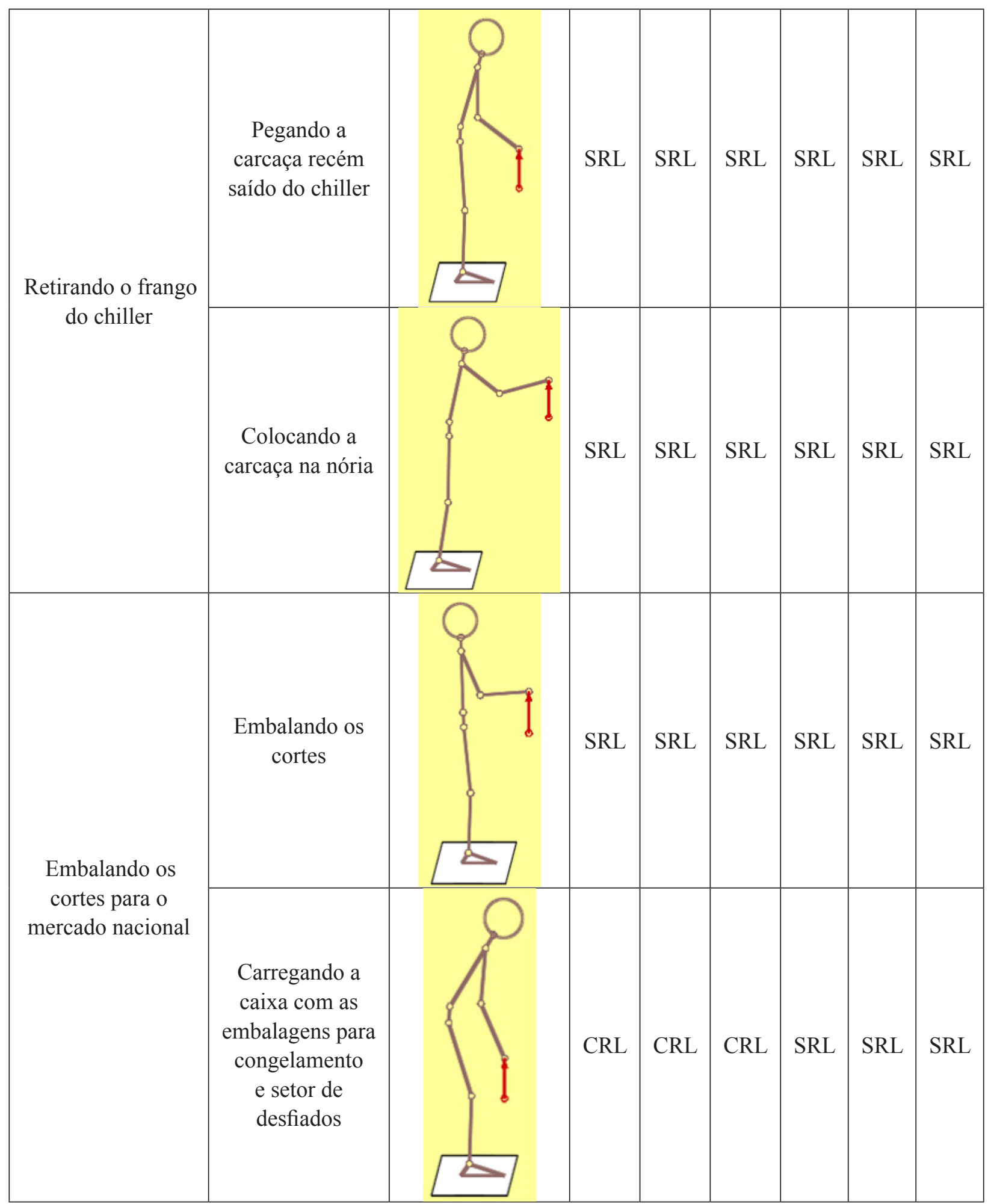




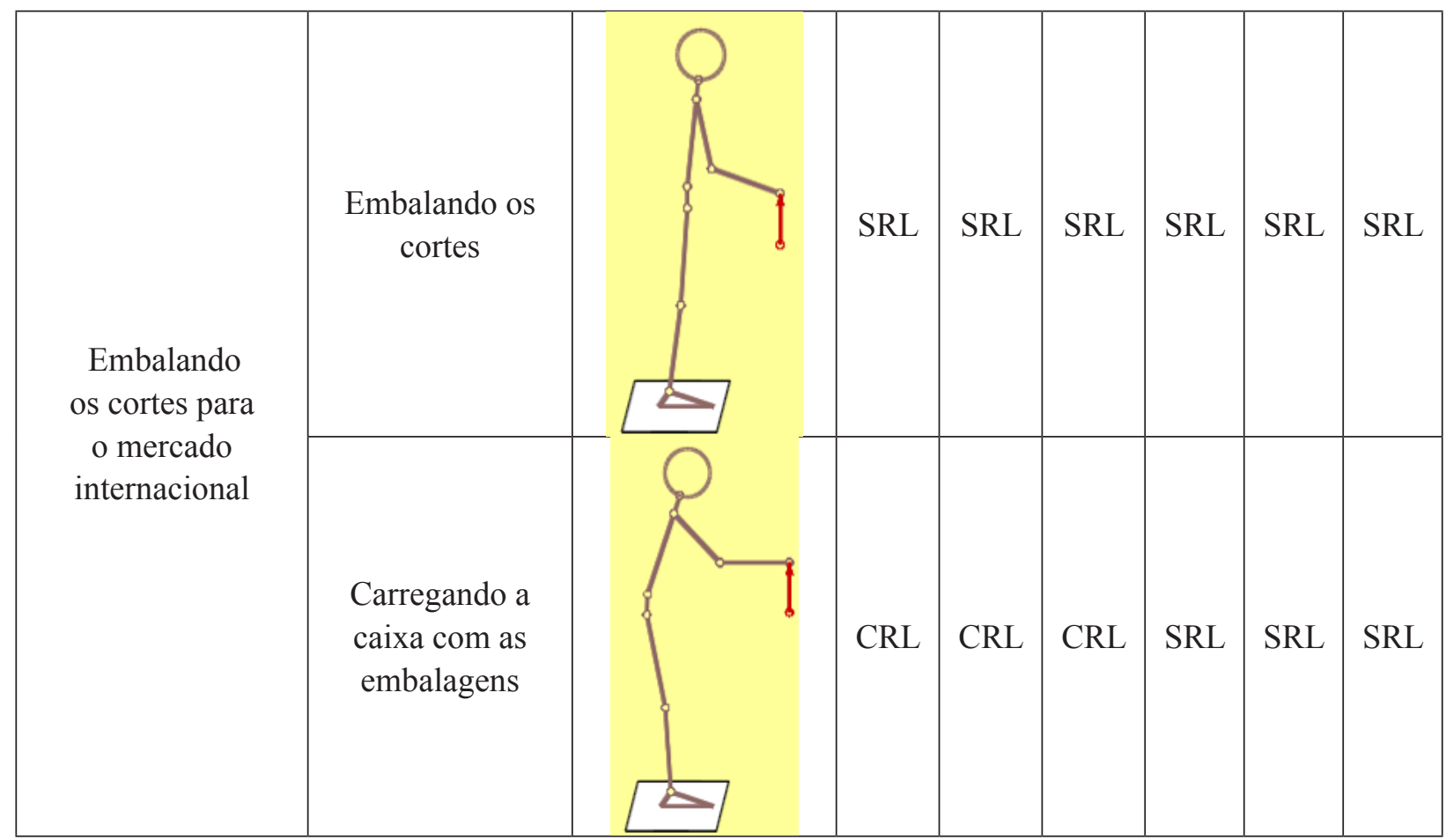

Pela desconsideração do programa com relação ao número de repetições realizadas pelos trabalhadores em cada atividade e pelo peso consideravelmente leve do frango, a maioria dos funcionários analisados pelo programa bidimensional não esteve sob risco de lesão nas articulações. Caso o programa considerasse o número de repetições, provavelmente os resultados poderiam ser diferentes, no entanto, mesmo sem essas considerações, foi verificado o risco de lesão no cotovelo, ombro e principalmente dorso durante o carregamento de caixas com peças de frangos, advindas tanto da sala de corte para mercado nacional, sala de corte para exportação e setor de desfiados.

Sant'Ana \& Walger (2002), estudando a análise postural dos trabalhadores de abatedouro de frango, concluíram que eles estão expostos ao risco de lesão no ombro, punho, coluna cervical e coluna lombo-sacra por causa do trabalho em pé estático, movimentos repetitivos dos membros superiores e tronco com postura inadequada.

Problemas relacionados a distúrbios ou patologias no segmento L5/S1 da coluna não foram verificados no abatedouro estudado. Acredita-se que isso seja devido ao baixo peso dos frangos e das caixas, que variam de 10 a $20 \mathrm{~kg}$.
Para Sant'Ana \& Walger (2002), todos os trabalhadores atuantes em abatedouros deveriam passar por um estudo ergonômico, com um exame médico para fazer uma análise antropométrica e dinamométrica, para se saber as capacidades físicas dos trabalhadores e adotar ações de melhoria na qualidade de vida pela adequação dos trabalhadores a funções que correspondem às suas condições ergonômicas.

\section{CONCLUSÃO}

De posse dos dados analisados, conclui-se que o descarregamento das caixas de frangos do caminhão, limpeza do setor de escalda e depenagem assim como o ato de erguer e empurrar as caixas dos vários setores para a área de congelamento oferecem riscos para a postura, assim como o carregamento de caixas com peças de frangos, advindas tanto da sala de corte e setor de desfiados pode lesionar o cotovelo e ombro dos trabalhadores.

Desta forma, sugere-se um maior treinamento para conscientizar os funcionários da necessidade de empregar posturas corretas, da adoção de ginástica laboral em um número maior de intervalos bem como do rodízio de atividades para eliminar os efeitos que o carregamento de peso e as

\section{REVENG


posturas inadequadas ocasionam no corpo destes trabalhadores.

\section{AGRADECIMENTOS}

À Fundação de Amparo à Pesquisa do Estado de Minas Gerais (Fapemig), à Capes (Coordenação de Aperfeiçoamento de Pessoal de Nível Superior), ao $\mathrm{CNPq}$ (Conselho Nacional de Desenvolvimento Científico e Tecnológico) e à Universidade Federal de Viçosa (UFV).

\section{REFERÊNCIAS BIBLIOGRÁFICAS}

BARTH, D.C. ; GUIMARÃES, L.B. de M. ; CATEN, C.S.T. . Análise do impacto do rodízio nos trabalhadores na desossa de frango. In: Lia Buarque de Macedo Guimarães. (Org.). Macroergonomia: colocando conceitos em prática - aplicação em processos. 1 ed. Porto Alegre: FEENG, v.2, p.1-27, 2010.

COUTO, H.A. Ergonomia aplicada ao trabalho: manual técnico da máquina humana. 2. Belo Horizonte: ERGO Editora, 1996.

DEFANI, J.C. Avaliação do perfil antropométrico e análise dinamométrica dos trabalhadores da agroindústria do setor de frigoríficos e abatedouros: o caso da Perdigão Carambeí.
2007. 143p. Dissertação (Mestrado em Engenharia de Produção) - Universidade Tecnológica Federal do Paraná.

DELWING, E.B. Análise das condições de trabalho em uma empresa do setor frigorífico a partir de um enfoque macroergonômico. 2007. 132p. (Dissertação de mestrado).

DUL, J; WEERDMEESTER, B. Ergonomics for beginners - A quick reference guide. London: Taylor \& Francis, 1994. 133p.

IIDA, I. Ergonomia: projeto e produção. São Paulo: Edgard Blucher, 2005. 632p.

OLIVER, J. Cuidados com as Costas: Um Guia para Terapeutas. São Paulo: Manole. 1999. 162p.

SANT'ANA, M.A. ; WALGER, C.A.P. . Avaliação de um Posto de Trabalhos em um Frigorifico de Aves. In: XI Jornada Farmâceutica de Umuarama VI Jornada de Internacional de Umuarama e V Mostra de Trabalhos Científica. 2002. Umuarama. Anais... Universidade Paranaense. Umuarama. 2002.

WILSON, J.e CORLETT, N. Evaluation of Human Work: A Practical Ergonomics Methodology. London: Taylor e Francis, 1995. 1119p. 